\title{
Bladder Exstrophy in the Developing World
}

Wiersma R: Overview of bladder exstrophy: a third world perspective. J Ped Surg 2008, 43:1520-1523.

Rating: • Of importance.

Introduction: The author of this article reviews the management of patients with exstrophy in a resource-poor environment of South Africa over a 23-year period of time. The study is retrospective in nature.

Aims: The author used this study to evaluate the morbidity and mortality of this uncommon urologic condition in a developing country.

Methods: This study was a long-term retrospective study conducted in one of the poorest regions of the world: the KwaZulu-Natal region of South Africa.

Results: The majority of patients were born in rural environments as opposed to metropolitan environments. Twelve of 57 children died in the hospital, and overall mortality was $42 \%$. Of the survivors, urinary incontinence remained the most frequently cited complaint, and it adversely affected both schooling and social life.

Discussion: The prognosis of exstrophy is poor in resource-poor regions. Early referral, better antenatal screening, and better continence techniques will likely improve outcomes in this patient group in these regions of the world.

\section{Comments}

The KwaZulu-Natal region is home to multidrug resistant tuberculosis and high rates of HIV/AIDS. It remains one of the poorest regions in the world. In contrast to developed countries where the infant mortality rates associated with exstrophy approach that of the general population, children born with exstrophy in developing countries face a significant risk of death associated with this condition. The specific reasons for this are largely infectious in nature. For those survivors, the morbidity of exstrophy is similar to that seen in the West, with urinary incontinence being a primary concern. Other investigators have noted an increased incidence of congenital anomalies, including exstrophy in countries affected by civil war [1]. In comparison to New York State, the incidence of exstrophy in the KwaZulu-Natal region is higher than expected, suggesting a possible association between poverty and exstrophy [2]. Whether the dissemination of more recent combination surgical techniques, such as the Mitchell (complete primary exstrophy repair) or Kelly (radical soft tissue exstrophy repair), will positively impact these outcomes in a resource-poor region remains to be seen.

\section{Acknowledgment}

Dr. Richard Grady is an Associate Professor at the Department of Urology, University of Washington School of Medicine. He is also the Director of Clinical Research at the Division of Pediatric Urology, Seattle Children's Hospital. Correspondence can be sent to 4800 Sandpoint Way, NE, Seattle, WA 98105, USA; e-mail: richard. grady@seattlechildrens.org.

\section{Disclosure}

Dr. Grady is an advisory board member and clinical investigator for Q-Med, Inc.

\section{References}

1. Ahuka OL, Toko RM, Omanga Fu, Tshimpanga BJ: Congenital malformations in the North-Eastern Democratic Republic of Congo during Civil War. East Afr Med J 2006, 83:95-99.

2. Caton AR, Bloom A, Druschel CM, Kirby RS: Epidemiology of bladder and cloacal exstrophies in New York State, 1983-1999. Birth Defects Res A Clin Mol Teratol 2007, 79:781-787. 